\title{
FUTURE DIRECTIONS FOR RESEARCH AND TREATMENT OF OSTEOARTHRITIS
}

\author{
Charles J. Malemud ${ }^{1}$, and Victor M. Goldberg ${ }^{2}$ \\ ${ }^{1}$ Departments of Medicine and ${ }^{2}$ Orthopaedics, Case Western Reserve University School of Medicine, 10900 Euclid Avenue, \\ Cleveland, Ohio 44106-4946
}

\section{TABLE OF CONTENTS}

1. Abstract

2. Introduction

3. Potential pathways for therapeutic intervention in the OA process

3.1 Pathogenesis of $O A$

3.2. Destruction of articular cartilage in $O A$

3.3. Dysregulation of articular cartilage homeostasis by up-regulation of matrix metalloproteinases (MMP) gene expression by synoviocytes and chondrocytes

3.4. Molecular characterization of the cartilage ECM protein degradation

3.5. Inhibition of inducers of MMP gene up-regulation

3.6. Repair of articular cartilage in $O A$

3.6.1. Future biologic regenerative treatments of articular surfaces

3.6.1.1. Tissue engineering

3.6.1.2. Genetic engineering

4. Acknowledgment

5. References

\section{ABSTRACT}

Future directions in the research and treatment of osteoarthritis (OA) will be based on the emerging picture of pathophysiological events that govern the initiation and progression of OA. The fundamental event resulting in the destruction of articular cartilage in OA arises from an imbalance between anabolic and catabolic pathways. The extracellular matrix (ECM) of cartilage is degraded by matrix metalloproteinases (MMPs) induced by cytokines. Cytokines also blunt chondrocyte compensatory synthesis pathways required to restore the integrity of the degraded ECM. Inhibition of the MMPs, their activators, and cytokines that induce MMP gene up-regulation would appear to be fertile targets for drug development in the treatment of OA. Restoration of damaged articular surfaces via tissue engineering strategies which could employ chondroprogenitor cells in biomatrices appropriate for transplantation to cartilage surfaces appears feasible. A reduction in cytokine-mediated up-regulation of MMP gene expression as well as augmentation of cartilage ECM biosynthesis may also be possible by employing the principles of gene transfer using suitable vectors that establish long-term stable expression of genes which suppress MMPs while at the same time supporting cartilage ECM biosynthesis.

\section{INTRODUCTION}

Recent studies have indicated several promising areas for improvement of the clinical symptoms of osteoarthritis (OA) As a departure from past therapies primarily involving the use of anti-inflammatory drugs such as corticosteroids and non-steroidal anti-inflammatry drugs (NSAIDs), several new modes of experimental OA therapy are based on an emerging understanding of the pathophysiological mechanisms underlying the OA disease process (1-3) as well as the host response to antiinflammatory agents which provide the patient with symptomatic relief from pain and swelling of synovial joints. For example, the emergence of cyclooxygenase II (COX II) inhibitors (4-6) supports the effectiveness of nonsteroidal anti-inflammatory drugs (NSAIDs) in treating the symptoms of OA while sparing toxicity to the intestinal mucosa and kidney which in the past has limited the longterm use of NSAIDs in the treatment of chronic OA. NSAIDs may also provide symptomatic relief from the pain and swelling of the inflammatory component of $\mathrm{OA}$ by blocking tumor necrosis factor-alpha (TNF-alpha) augmentation of prostaglandins (see below). While no effective therapy exists at present which modulates the key markers of $\mathrm{OA}$ disease progression (i.e. cartilage degradation and osteophyte formation), several lines of research have focused attention on potential pathways for intervention in the destruction of articular cartilage and bone in arthritis $(7,8)$.

\section{POTENTIAL PATHWAYS FOR THERAPEUTIC INTERVENTION IN THE OA PROCESS}

\subsection{Pathogenesis of $O A$}

Whether OA is initiated in synovial joint articular cartilage or as a result of weakening of the subchondral bone by microfracturing remains controversial to this day and experimental results exist to support both possibilities (7, 9-11). Whatever the initial insult, the final common pathway in $\mathrm{OA}$ results in the destruction of articular cartilage, joint remodeling and subchondral bony sclerosis (12). 


\subsection{Destruction of articular cartilage in $\mathrm{OA}$}

Loss of articular cartilage in OA is characterized radiographically by joint space narrowing (13). The process of cartilage destruction in $\mathrm{OA}$ is basically an error in cartilage homeostasis. Normally, anabolic and catabolic pathways governing the synthesis and maintenance of extracellular matrix (ECM) are in balance. While articular cartilage ECM protein turnover is quite modest under normal conditions, chondrocytes are able to synthesize and integrate into the ECM those ECM proteins such as proteoglycans, collagen, fibronectin, integrins and other adhesive proteins which enable cartilage to maintain high tensile strength and low compressibility under load throughout the life-span of the individual. Hyaluronan and lubricating glycoproteins which are synthesized by primarily by synovial lining cells maintain low frictional resistance along the cartilage surface and reduce the tendency of the weight-bearing surfaces to abrade each other. Mechanical alterations which could compromise this homeostasis would alter the capacity of cartilage to maintain the anabolic and catabolic pathways in balance. Thus, normal cartilage ECM responding to aberrant mechanical forces could be the key initiating event in the pathogenesis of OA. Certainly this is a testable hypothesis and several laboratories are now examining how chondrocytes respond to mechanical pressure and loading by analyzing how stress affects chondrocyte homeostasis (14).

3.3. Dysregulation of articular cartilage homeostasis by up-regulation of matrix metalloproteinase (MMP) gene expression by synoviocytes and chondrocytes

The significant up-regulation of MMP gene expression early in the OA process is seen in animal models of OA (15-17). This suggests that MMP gene expression is relevant to OA pathogenesis. Significant increased MMP activity has also been measured in human cartilage sampled from patients with debilitating OA (1820). These results have led to the conclusion that a therapeutic intervention designed to inhibit MMP activity could be a useful specific OA therapy $(2,3,21-23)$.

Among the MMPs which have been implicated in this process, MMP-1 (collagenase-1), MMP-3 (stromelysin-1), MMP-2 and MMP-9 (gelatinases), MMP-8 (neutrophil collagenase), MMP-13 (collagenase-3) and aggrecanase have received the most experimental attention (24-30). MMP-7 (matrilysin), an MMP with broad substrate cleavage activity is also increased in OA (31). The lysosomal hydrolase, Cathepsin B, is up-regulated in OA $(32,33)$ and may also serve to activate other proteinases active in the degradation of cartilage in OA (32).

Normally, the activity of these MMPs is quite low in articular cartilage with regulatory control over their synthesis and activation responsible for the low turnover of ECM proteins. However, cytokines such as IL-1, TNFalpha and LIF whether they be produced by activated synoviocytes, mononuclear cells or by articular cartilage itself significantly up-regulates MMP gene expression $(25,34,35)$. Chondrocyte and synoviocyte MMPs are synthesized as latent pro-enzymes (36,37). Several activation pathways have been implicated in the OA process and these activation events may be targets for therapeutic intervention. One pathway of interest involves the production of plasmin via plasminogen activator (PA) which is synthesized by chondrocytes (38). Both the PA forms found in urine (uPA) and the tissue form of PA (tPA) are produced by chondrocytes, but the uPA form may be more critical in terms of cartilage breakdown $(37,38)$. The plasmin/PA pathway is held in check by plasminogen activator inhibitors (PAI) Two forms of PAI, PAI-1 and PAI-2 regulate the level of plasmin. However, the plasmin level in OA cartilage is significantly increased over normal and this account for the significant level of active MMP produced by chondrocytes derived from OA cartilage (2430). Another MMP proenzyme activator was recently reported in articular cartilage which may be similar to the insulinase superfamily of metalloendopeptidases (39). More recently, other activation pathways have implicated the membrane-type MMPs (MT1-MMP; MMP-14) which were shown to activate gelatinase A and collagenase-3 (40) and also to be expressed in human OA cartilage (41). MT1MMP has also been shown to cleave recombinant aggrecan in vitro (42). In addition, stromelysin-1 was shown to activate procollagenases (43) and PA (38). The results of these studies, when considered together with other data, strongly suggest a complex series of gene regulatory and activation events occurring during OA such that that no single inhibitor of pro-MMP gene expression or activation will suffice to reduce cartilage degradation. A variable appearance of aggrecan neoepitopes, VDIPEN and NITGE, produced by degradation with MMPs and aggrecanase, respectively, occur as a function of disease progression and severity in murine models of arthritis (44) and support this contention.

The level of latent MMP synthesis in OA cartilage greatly exceeds the up-regulation of tissue inhibitor of metalloproteinases gene expression (TIMP-1, TIMP-2, TIMP-3) that also occurs during the OA process $(37,45,46)$. TIMPs role in controlling cartilage ECM protein turnover is to inhibit MMPs once they are activated $(37,47,48)$, but the amount and TIMP isoform produced by OA cartilage is insufficient to inhibit the level of MMPs produced by chondrocytes. Thus, TIMP-1 RNA expression by chondrocytes derived from OA cartilage was elevated compared to chondrocytes derived from non-OA cartilage, while TIMP-2 RNA expression was comparable in both cases (48). This may help explain why cartilage proteolysis occurs in OA. In addition, once MMPs are activated and not effectively inhibited by TIMPs, MMPs degrade both the endogenous and newly synthesized ECM proteins (49). The degradation of newly synthesized ECM proteins is particularly significant since these ECM proteins synthesized by chondrocytes to replace the ECM proteins lost via MMP degradation are not efficiently integrated into the depleted ECM. Recent advances in understanding how activated MMP-3 (stromelysin-1) and TIMP-1 interact at the molecular level may suggest new tactics for designing synthetic TIMPs which are more effective MMP inhibitors than the naturally occurring TIMP forms (50).

\subsection{Molecular characterization of the cartilage ECM protein degradation \\ The articular cartilage ECM ensures its resistance} to compression. The integrity of the tissue is dependent on 
the complex network of Type II collagen, proteoglycans, and accessory proteins such as fibronectin. All of these macromolecules are synthesized by the resident chondrocytes and the individual macromolecules integrated into the existing ECM. Aggrecan is the most significant of the proteoglycans of articular cartilage since it forms aggregates with cartilage hyaluronan stabilized by link protein (51) which inhibits diffusion of aggrecan from the cartilage ECM. Loss of aggrecan via proteolytic degradation significantly compromises the cartilage ECM mechanical properties.

In vitro studies have shown that the interglobular domain (IGD) of aggrecan is particularly sensitive to activated stromelysin-1 (52). Other proteinases, namely "aggrecanase", MMP-8 and MMP-13 also degraded aggrecan in the IGD (53-55). The aggrecanase-1 gene was recently cloned from cartilage (56), and has structural characteristics similar to the adamalysin (ADAMTS) family of proteins (56). TIMP-1 is a potent inhibitor of aggrecanaase-1 $\left[\mathrm{IC}_{50}, 210 \mathrm{nM}\right](56)$. Aggrecan cleavage products produced by these various enzymes suggest, however, that some differences in the actual site of cleavage within the IGD exist. These studies provide favorable indications that synthetic inhibitors of IGDsensitive proteases may be developed.

Since OA synovial fluid aggrecan fragments contain the aggrecan N-terminus consistent with aggrecanase-mediated cleavage, this MMP becomes an important target for intervention in the $\mathrm{OA}$ process. However, as in the case of MMP activators, the eventual release of aggrecan fragments from cartilage is likely to occur via diffusion as a result of several proteolytic enzyme activities, perhaps acting sequentially or synergistically. This will make specific inhibitory targets more difficult to isolate.

While aggrecan fragmentation is germane to the OA process, the final dissolution of cartilage requires collagen to be lost as well. A mammalian collagenase (MMP-1) degraded the helical domain of Type II collagen $(20,57,58)$. A Type II-specific collagenase was found in cultured chondrocyte lysates (59). Stromelysin-1 (MMP-3) also degrades Type IX and Type XI collagen (60). These collagen isoforms interact to produce hybrid fibrils with the major Type II collagen fibril in cartilage. Taken together, the evidence indicates that Type II collagen degradation is ultimately regulated by chondrocyte collagenases and likely accounts for the initial fragmentation of cartilage collagen in OA. The final dissolution of cartilage collagen, however, is likely mediated by the activity of "gelatinases" which are produced by chondrocytes (29) and whose activity is increased in the fibrillated component of OA cartilage (29, also see chapter by RL Smith, this volume). Since link protein, fibronectin and the small leucine-rich proteoglycans, decorin and biglycan are also degraded by proteinases within OA cartilage (61-63) a further destabilization of the cartilage ECM ensues. Fibronectin degradation fragments are capable of markedly altering chondrocyte metabolism (63, also see chapter by $G$ Homandberg, this volume). Future directions for research in this area may focus on the use of oral inhibitors of MMPs to limit the proteolytic degradation of cartilage ECM. Indeed, orally administered inhibitors of collagenase (MMP-1) and stromelysin-1 (MMP-3) have shown efficacy in animal models of OA $(2,3)$.

\subsection{Inhibition of the inducers of MMP gene up- regulation}

Human chondrocytes derived from the "resident" cartilage of OA femoral heads failed to express MMP-3 unless treated with recombinant human IL-1-alpha [rhIL-1alpha] (64). RhIL-1-alpha significantly up-regulated MMP3 steady-state mRNA and the mRNA was molecularly identical to MMP-3 derived from synovium (64). TNFalpha also upregulated MMP gene expression in human chondrocyte-like cultures (65). The neutralization of IL-1alpha and/or TNF-alpha up-regulation of MMP gene expression appears to be a logical development in the potential medical therapy of OA. Indeed, recombinant IL1-alpha receptor antagonists (ILRA) and soluble IL-1alpha receptor proteins have been tested in both animal models of OA for modification of OA progression and on surrogate measurements such as MMP-3 gene expression (21-23, also see chapter by J Martel-Pelletier et al., this volume ). Soluble IL-1-alpha receptor antagonist suppressed MMP-3 transcription in the rabbit synovial cell line HIG-82 (23) suggesting that ablation of rabbit OA cartilage changes may occur when suppression of MMP-3 gene expression in synoviocytes is the target of gene therapy. Experimental evidence showing that neutralizing TNF-alpha suppressed cartilage degradation in arthritis (66) also support such strategies for limiting cartilage destruction by targeting the MMP-inducing cytokine instead of the MMP itself. The important role of TNFalpha in OA may emerge from the fact that human articular chondrocytes from OA cartilage expressed a significantly higher number of the p55 TNF-alpha receptor which could make OA cartilage particularly susceptible to TNF-alpha degradative stimuli (67). In addition, OA cartilage produced more TNF-alpha and TNF -alpha convertase enzyme (TACE) mRNA than normal cartilage (68). Indeed, by analogy to the strategy directed towards inhibiting IL-1alpha induction of MMP gene expression by IL-1 receptor antagonist, an inhibitor to the p55 TNF-alpha receptor may also provide a mechanism for abolishing TNF-alphainduced degradation of cartilage ECM by MMPs (see section 3.6.1.2). Since TACE is the regulator of TNF-alpha activity, strategies designed to limit the activity of TACE might also prove efficacious in suppressing cartilage degradation in OA. IL-1-alpha and TNF-alpha inhibition of chondrocyte compensatory biosynthesis pathways which further compromise cartilage repair must also be thwarted, perhaps by employing stimulatory agents such as transforming growth factor-beta or insulin-like growth factor-I (69) or NSAIDs which can augment growth factor production (70). The basis for NSAID therapy in OA even in the presence of cartilage or synovial cytokines such as TNF-alpha is based, in part, on the studies which have shown marked upregulation of prostaglandins by TNFalpha $(34,71,72)$, but other mechanisms are possible as well, including effects on IL-1 and growth factors (70). Prostaglandins produce the pain and swelling of synovial 
joints which are fundamental clinical symptoms of OA pathophysiology. Taken together with other studies, these indices of OA pathology may be altered by agents which inhibit the ability of IL-1 and TNF-alpha to up-regulate MMP gene expression.

\subsection{Pathways governing cartilage repair}

The statement of Hunter (73) that, "ulcerated cartilage is a troublesome thing, once destroyed is not repaired" remains true to this day. Conceptually, repair is a result in most connective tissues of an inflammatory response that requires a vascular supply. However, chondrocytes are embedded in the ECM which excludes them from systemic vascular circulation and as previously discussed (Section 3.2) has a complex molecular structure. Cartilage injuries are usually of 2 types (74). In one type, mechanical damage is confined to the ECM components without damage to the chondrocytes or collagen scaffolding. In this situation chondrocytes synthesize proteoglycans to completely restore the ECM. By contrast, in the second type of cartilage injury, chondrocytes and the ECM including the collagen scaffolding are damaged by blunt or penetrating trauma. In this event chondrocytes retain the potential for repair, but this ability depends on the extent of injury, the topographical location of the injured cartilage, the age of the animal and whether or not the injury extends into the vascular subchondral marrow cavity (75). When the injury does not penetrate to subchondral bone but significantly destroys the collagen fibers of the ECM, the chondrocytes have little or no capacity to repair the damage. However, injuries to cartilage that encompass the full thickness of the tissue and which penetrate subchondral marrow do have the capacity to repair. The repair that ensues is variable and depends on the capacity of the resident chondroprogenitor cells (76, also see chapter by S. Frenkel \& P. E. Di Cesare, this volume).

Data from this and other laboratories have defined the key elements of cartilage repair and regeneration (77-79) and provide the impetus for the development of new strategies to support cartilage regeneration after injury and in OA. The fundamental stages of cartilage injury have been delineated. Initially, a penetrating injury to the marrow cavity results in marrow hemorrhage into the base of the defect. This marrow eruption is critical in order to provide the defect with chondroprogenitor cells that have the potential to aggregate, expand and differentiate into cartilage. This paradigm has as its basis the fundamental mechanisms resulting in the development of the embryonic skeletal (80). In the embryonic development model, skeletal structure begins with a solid, primitive cartilaginous structure. The cartilage model (or anlage) differentiates into a structure in which chondrocytes at the surface are arrested in a specific cartilage phenotype, while the central chondrocytes progress to a hypertrophic stage, are replaced by marrow and vasculature and yet another set of progenitor cells which differentiate into osteoblasts. It is our concept that a critical number of chondroprogenitor cells must be delivered into an articular cartilage defect and rapidly differentiate into a plug of chondrocytes possessing an embryonic phenotype. These chondrocytes must develop at the surface of hyaline cartilage and stabilize their phenotype there, while at the bottom of the defect chondrocytes must eventually undergo hypertrophy in order to regenerate the tidemark in subchondral bone (76). Recent evidence indicated that articular cartilage defects do not regenerate because of an insufficient number of chondroprogenitor cells experimentally- delivered to the defect. Rather additional components of the regeneration mechanism are impaired.

These include, a lack of vascular supply, slow ECM turnover, unique biomechanical properties which must be satisfied (and which are apparently not met), tissue anisotropy and a complex tissue organization with specific zonal characteristics critical in the functioning of articular cartilage which in the current experimental protocols cannot be accurately duplicated by the repair cells (81).

\subsubsection{Future directions for biologic regenerative treatments of articular surfaces \\ 3.6.1.1. Tissue engineering \\ The application of biologic treatments to restore} cartilage articular surfaces in OA may depend on connecting tissue engineering principles to orthopaedics. Tissue engineering has a primary goal of restoring, maintaining or improving tissue function by employing the principles of engineering and life sciences (75). Tissue engineering merges the fields cell biology, engineering, material science and surgery to synthesize new functional tissue using cells, active biomatrices and signaling molecules. This treatment strategy is already in clinical practice in the development of artificial skin for the treatment of burns. How could such a strategy be employed for the treatment of OA? The application of tissue engineering to the repair of articular surface defects in OA or after injury will require that viable cells be transplanted to the injured tissue site. Experimental and preliminary clinical studies have shown that both committed differentiated chondrocytes and undifferentiated chondroprogenitor cells placed in a supportive carrier when used to repair a defect, survive and produce an appropriate ECM $(76,82,83)$. Bittberg et al. $(84,85)$ reported on the use of autologous chondrocyte transplantation under a sutured periosteal flap to repair deep cartilage defects. The early outcome of these studies suggested that approximately $80 \%$ of the patients were clinically improved and the biopsies of the repaired tissue have the appearance of viable hyaline cartilage. However, other experimental studies suggest that the long-term fate of these repaired articular surfaces is characterized by early degeneration and loss of structural integrity (86). Clearly the long-term durability of this treatment approach remains in doubt and additional studies will be required to define whether strategies such as these will be useful in the restoration of degenerated articular surfaces.

Another approach to cell-based treatment strategies is to experimentally employ chondroprogenitor cells isolated from periosteum and bone marrow to repair large full and partial thickness defects of articular cartilage $(76,80,83)$. These progenitor cells were isolated in vitro, 
dispersed in a Type I collagen gel and transplanted into large full and partial thickness defects of the medial femoral condyle of adult rabbits. Within the first 4 weeks, these chondroprogenitor cells differentiated into chondrocytes and appeared to recapitulate an early embryonic lineage sequence. The cells at the surface appeared to maintain their hyaline articular cartilage phenotype and synthesized a metachromatic staining ECM, indicative of sulfated-proteoglycans. The cells at the base of the defect appeared hypertrophic to be replaced by vascularized cancellous bone. The regenerative tissue satisfactorily integrated with the original uninjured host cartilage. However, one year after transplantation, the surface cartilage produced in the defect by the transplanted cells became roughened and thinner than the surrounding host articular cartilage. These early experiments confirmed important concepts regarding criteria for successful cartilage regeneration. But why does the cartilage in the defect undergo changes? It is clear that a successful outcome for articular cartilage regeneration requires a recapitulation of embryonic events. The central component is the number and quality of the chondroprogenitor cells provided to the surface. There must be a suitable, supportive and flexible delivery vehicle and the appropriate biological and mechanical cues managed to support the differentiation of the transplanted cells to adult hyaline cartilage. Most importantly, the durability of this repair tissue must be designed to enable it to withstand the rigors of an intense mechanically aggressive environment. How could this be accomplished experimentally? Recent studies from this laboratory have addressed the use of hyaluronic acid (HA)-based polymers as biologic carriers that can be employed to stabilize chondroprogenitor cells, encompass growth factors and enhance the overall natural healing process $(75,87,88)$. The HA-based polymers appear to recreate an embryonic-like environment (i.e. Wharton's jelly) where host progenitor cells can regenerate damaged articular surfaces and underlying bone. These polymers were used alone and in combination with autologous chondroprogenitor cells to repair large osteochondral defects in the femoral condyle of young adult rabbits. The results from these studies indicated that HA-based polymers provided an appropriate scaffolding and favorable microenvironment for the reparative process. At 12 weeks after transplantation, the base of the defects had regenerated cancellous bone and the tidemark, while the superficial layer showed evidence of phenotypically appropriate hyaline cartilage. These studies further suggested that the HA-based biomatrices may act not only as a carrier material for the cells, but may also possess "chondroinductive" and "chondroconductive" capabilities. Clearly additional studies will need to address the issue of the ideal combination of cells, biomatrices and growth factors to effectively tissue engineer articular surfaces destroyed in OA.

\subsubsection{Genetic engineering}

Genetic engineering offers another treatment approach to the regeneration of degenerative articular cartilage. The goal is to control the biological systems which are mediating the destructive processes in OA. Only by understanding how these complex pathways act and interact can genetic engineering prove successful (see Section 3.3). Furthermore, by using genes and gene products to drive the host's reparative processes it may be possible to restore functional articular surfaces. Genetic engineering provides a capability for targeting biologic agents to specific anatomic sites which maintains a local therapeutic level for a prolonged period of time. There are, however, several questions which must be answered to accomplish a successful gene therapy strategy $(1,89)$ and these studies will serve as the impetus for future research in this area. Among the questions to be answered are: 1) which genes to use?, 2) how to transfer the genes safely?, and 3) how to regulate their long-term expression?

There exist several experimental (90-92) and clinical $(93,94)$ studies exploring possible gene products which are involved in modifying either the immunologic or non-immunologic pathways that participate in the etiology of the rheumatic diseases. These gene products include, interleukin-1 receptor antagonist (IL-1Ra), soluble tumor necrosis factor receptor (sTNFR), and transforming growth factor-beta (TGF-beta). Experimental studies and clinical trials in RA suggested that transfer of the IL-1Ra gene to synoviocytes inhibited cartilage erosions $(91,93)$. By contrast, transfer of the sTNFR gene had little or no effect on either pannus invasion or cartilage degradation in arthritic SCID mice (95). Retroviral transfer of sTNFR to spleen cells recovered from mice with collagen-induced arthritis suppressed the capacity of these cells to transfer the disease to SCID mice (96). Clinical trials employing TNF receptor p55 in treating patients with RA showed a reduction in disease activity (97). TGF-beta transferred in a plasmid DNA system suppressed inflammation in an animal model of antigen-induced arthritis $(98,99)$. Gene transfer of TGF-beta may also be useful in this regard because it augments chondrocyte proteoglycan biosynthesis $(100,101)$.

A complete assessment of which vectors or effective gene delivery systems to use in the gene therapy of cartilage degeneration is beyond the scope of this review, however, a number of carriers have been explored (89). Viruses have been extensively used as vectors and the results have been favorable. The 3 types of viruses employed for this purpose have been retrovirus, adenovirus and adeno-associated virus. Some of the important issues related to virus as vectors are their antigenicity which results in a host immune response limiting the long-term usefulness, the randomness of their integration into the host cells genome and their potential cytotoxicity. Other possible vectors include "naked" DNA and ligand complexes $(89,102)$. Furthermore, whether genes or their vectors are delivered locally to a specific anatomically designated structure and confined to that space, or systemically administered will depend upon on the disease target. Clearly the safety of gene therapy is a central issue in the clinical application of this treatment strategy. However, to date no pathologic problems have resulted in ongoing human gene trials (89).

OA provides a disease model that potentially lends itself to gene treatment. In one animal model of canine knee OA, transfer of the IL-1Ra gene to synovium 
reduced the size and severity of the cartilaginous lesions (103). Another approach has been to transfer genes of this type to chondrocytes ex vivo. Although some success has been reported using this strategy, gene expression was transitory and gene expression undetectable by 4 weeks after transfer (104). Direct in vivo delivery of genes to chondrocytes is a technically difficult task because of the denseness of the cartilage ECM. Some success, however, has been reported using liposomes as the carrier material (105). Perhaps as important in the context of OA and the presence of degenerative cartilage is the use of geneenhanced restoration of the early hyaline cartilage lesions. TGF-beta is one cytokine that is under investigation for this purpose (89).

Long-term gene expression is an advantage in diseases such as OA because of the chronicity of the pathology. However, long-term gene expression has been difficult to accomplish because of cell turnover or death. Another approach could be the transfection of progenitor cells that would have long-term transgenic expression. This strategy has been evaluated in the murine hematopoietic stem cell with lifelong gene expression (106). The musculoskeletal system also provides a fertile area for this approach. As previously discussed, this laboratory has isolated osteochondroprogenitor cells and have used them to regenerate articular cartilage in experimental defects. The transfection of these progenitor cells with a transducing integrating viral vector is presently under investigation (B.Johnstone, personal communication).

The biologic restoration of articular surfaces in OA provides a unique treatment opportunity that not only addresses the repair of the destroyed articular cartilage surfaces, but also provides the basis for preventing the progression of the lesions as well. Whether cell-based tissue engineering or growth factor-mediated repair is used, the aetiopathogenesis of OA may be considered as a template to model the merging sciences of tissue and genetic engineering.

\section{ACKNOWLEDGMENT}

These studies were supported by grants from the National Institutes of Health.

\section{REFERENCES}

1. C.H. Evans \& P. D. Robbins: Potential treatment of osteoarthritis by gene therapy. Rheum Dis Clin North Am 25, 333-44 (1999)

2. E.J. Lewis, J. Bishop, K.M.K. Bottomley, D. Bradshaw, M. Brewster, M.J. Broadhurst, P.A. Brown, J.M. Budd, L. Elliott, A.K. Greenham, W.H. Johnson, J.S. Nixon, F. Rose, B. Sutton. \& K. Wilson: Ro 32-3555, an orally active collagenase inhibitor, prevents cartilage breakdown in vitro and in vivo. Br J Pharmacol 121, 540-6 (1997)

3. L.J. MacPherson, E.K. Bayburt, M.P. Capparelli, B.J. Carroll, R. Goldstein, M.R. Justice, L. Zhu, S.-I. Hu, R.A. Melton, L. Fryer, R. Goldberg, J.R. Doughty, S. Spirito, V. Blancuzzi, D. Wilson, E.M. O'Bryne, V. Ganu \& D.T. Parker: Discovery of CGS 27023A, a non-peptidic, potent, and orally active stromelysin inhibitor that blocks cartilage degradation in rabbits. J Med Chem 40, 2525-32 (1997)

4. J.B. Summers \& R.D. Dyer: Symposium new drugs for inflammatory allergic and immunologic diseases. Agents Actions 49 (Suppl), 45-7 (1998)

5. P. Needleman \& P.T. Manning: Interactions between the inducible cyclooxygenase (COX-2) and nitric oxide synthase (iNOS) pathways: implications for the therapeutic intervention in osteoarthritis. Osteoarthritis Cartilage 7, 367-70 (1999)

6. S. Abramson: The role of COX-2 produced by cartilage in arthritis. Osteoarthritis Cartilage 7, 380-1 (1999)

7. LS Lohmander: The role of molecular markers in monitoring joint cartilage breakdown and repair in osteoarthritis. In: Osteoarthritic disorders. Eds: Kuettner KE, Goldberg VM, American Association of Orthopaedic Surgeons, Rosemont, IL (1995)

8. F.A. Wollheim: Predictors of joint damage in rheumatoid arthritis. APMIS 104, 81-93 (1996)

9. E.L. Radin \& R.M. Rose: Role of subchondral bone in the initiation and progression of cartilage damage. Clin Orthop Relat Res 213, 34-40 (1986)

10. S. Mori, R. Haruff \& D.B. Burr: Microcracks in articular calcified cartilage of human femoral heads. Arch Pathol Lab Med 117, 196-8 (1993)

11. EL Radin, M Schaffler, G Gibson \& S Tashman: Osteoarthrosis as the result of repetitive trauma.

In: Osteoarthritic disorders. Eds: Kuettner KE, Goldberg VM, American Association of Orthopaedic Surgeons, Rosemont, IL (1995)

12. AL Schiller: Bones and joints. In: Pathology. Eds: Rubin E, Farber JL, Lippincott, Philadelphia, (1994)

13. PG Bullough (ed): Atlas of orthopaedic pathology with clinical and radiological correlations. $2^{\text {nd }}$ Ed. Gower Medical, NY (1992)

14. VC Mow, LA Setton, F Guilak \& A Ratcliffe: Mechanical factors in articular cartilage and their role in osteoarthritis. In: Osteoarthritic disorders. Eds: Kuettner KE, Goldberg VM, American Association of Orthopaedic Surgeons, Rosemont, IL (1995)

15. J.-P. Pelletier, J. Martel-Pelletier \& C. J. Malemud: Canine osteoarthritis: effects of endogenous neutral metalloproteoglycanases on articular cartilage proteoglycans. J Orthop Res 6, 379-88 (1988)

16. J.-P. Pelletier, F. Mineau, M.P. Faure. \& J. MartelPelletier: Imbalance between the mechanisms of activation and inhibition of metalloproteinases in the early lesions of experimental osteoarthritis. Arthritis Rheum 33, 1466-76 (1990)

17. L. Bonassar, K.A. Jeffries, E.H. Frank, V.L. Moore, M.W. Lark, E.K. Bayne, J. McDonnell, J. Olszewski, W. Hagmann, K. Chapman \& A.J. Grodzinsky: In vivo effects of stromelysin on the composition and physical properties of rabbit articular cartilage in the presence or absence of a synthetic inhibitor. Arthritis Rheum 38, 1678-86 (1995)

18. A.J. Fosang, K. Last \& R. A. Maciewicz: Aggrecan is degraded by matrix metalloproteinases in arthritis. Evidence that matrix metalloproteinase and aggrecanase activities can be independent. J Clin Invest 98, 2292-9 (1996)

19. M.W. Lark, E.K. Bayne, J. Flanagan, C.F.. Harper, L.A. Hoerrner, N.I. Hutchinson, I.I. Singer, S.A. Donatelli, J.R. 
Weidner, H.R. Williams, R.A. Mumford \& L.S. Lohmander: Aggrecan degradation in human cartilage. Evidence for both matrix metalloproteinase and aggrecanase activity in normal, osteoarthritic and rheumatoid joints. J Clin Invest 100, 93-106 (1997)

20. R.C. Billinghurst, L. Dahlberg, M. Ionescu, A. Reiner, R. Bourne, C. Rorabeck, P. Mitchell, J. Hambor, O. Diekmann, H. Tschesche, J. Chen, H. Van Wart \& A. R. Poole: Enhanced cleavage of Type II collagen by collagenases in osteoarthritic cartilage. J Clin Invest 99, 1534-45 (1997)

21. V.M. Baragi, R.R. Renkiewicz, H. Jordan, J. Bonadio, J.W. Hartman \& B.J. Roessler: Transplantation of transduced chondrocytes protects articular cartilage from interleukin 1-induced extracellular matrix degradation. $J$ Clin Invest 96, 2454-60 (1995)

22. U. Müller-Ladner, C.R. Roberts, B.N. Franklin, R.E. Gay, P.D. Robbins, C.H. Evans \& S. Gay:

Human IL-1Ra gene transfer into human synovial fibroblasts is chondroprotective. J Immunol 158, 3492-8 (1997)

23. F. Mehraban \& S. Kasturi: Gene transfer of type 1 interleukin-1 receptor extracellular-domain complementary DNA into rabbit synovial cell line HIG-82 results in cellular blockade of interleukin-1 signal transduction. Arthritis Rheum 41, 515-24 (1998)

24. G.N. Smith Jr, K.A. Hasty, L.P. Yu, Jr, K.S. Lamberson, E.A. Mickler \& K. D. Brandt: Cleavage of Type XI collagen fibers by gelatinase and by extracts of osteoarthritic canine cartilage. Matrix 11, 36-42 (1991)

25. A. Mauviel: Cytokine regulation of metalloproteinase gene expression. J Cell Biochem 53, 288-95 (1993)

26. P.G. Mitchell, H.A. Magna, L.M. Reeves, L.L. Lopresti-Morrow, S.A. Yocum, P.J. Rosner, K.F. Geoghegan \& J.E. Hambor: Cloning, expression, and type II collagenolytic activity of matrix metalloproteinase-13 from human osteoarthritic cartilage. J Clin Invest 97, 761-8 (1996)

27. A.A. Cole, S. Chubinskaya, B. Schumacher, K. Huch, G. Cs-Szabo, J. Yao, K. Mikecz, K.A. Hasty \& K.E. Kuettner: Chondrocyte matrix metalloproteinase-8. Human articular chondrocytes express neutrophil collagenase. $J$ Biol Chem 271, 11023-6 (1996)

28. P. Reboul, J.-P. Pelletier, G. Tardif, J.-M. Cloutier \& J. Martel-Pelletier: The new collagenase, collagenase-3, is expressed and synthesized by human chondrocytes but not by synoviocytes. A role in osteoarthritis. J Clin Invest 97 , 2011-9 (1996)

29. K. Tsuchiya, W.J. Maloney, T. Vu, A.R. Hoffman, P. Huie, R. Sibley, D.J. Schurman. \& R.L. Smith: Osteoarthritis: differential expression of matrix metalloproteinase-9 mRNA in nonfibrillated and fibrillated cartilage. J Orthop Res 15, 94-100 (1997)

30. E.C. Arner, C.P. Decicco, R. Cherney \& M.D. Tortorella: Cleavage of native cartilage aggrecan by neutrophil collagenase (MMP-8) is distinct from endogenous cleavage by aggrecanase. J Biol Chem 271, 9294-9 (1997)

31. S. Ohta, K. Imai, K. Yamashita, T. Matsumoto, I. Azumano \& Y. Okada: Expression of matrix metalloproteinase-7 (matrilysin) in human osteoarthritic cartilage. Lab Invest 78, 79-87 (1998)
32. D.J. Buttle, C.J. Handley, M.Z. Ilic, J. Saklatvala, M. Murata \& A.J. Barrett: Inhibition of cartilage proteoglycan release by a specific inactivator of Cathepsin B and an inhibitor of matrix metalloproteinases. Evidence for two converging pathways of chondrocyte-mediated proteoglycan degradation. Arthritis Rheum 36, 1709-17 (1993)

33. F. Mehraban, M.H. Tindal, M.M. Profitt \& R.W. Moskowitz: Temporal pattern of cysteine endopeptidase (Cathepsin B) expression in cartilage and synovium from rabbit knees with experimental osteoarthritis: Gene expression in chondrocytes in response to interleukin-1 and matrix depletion. Ann Rheum Dis 56, 108-15 (1997)

34. J-P Pelletier, J Martel-Pelletier, CJ Malemud: Effects of non-steroidal anti-inflammatory drugs and corticosteroids on cartilage metabolism in rheumatoid arthritis and osteoarthritis. In: Nonsteroidal anti-inflammatory drugs. Mechanisms and clinical use. $2^{\text {nd }}$ Edition, Eds: Lewis AJ, Furst DE, Marcel Dekker, NY (1994)

35. M. Zafarullah, J.-P. Pelletier J.-M. Cloutier \& J MartelPelletier: Elevated metalloproteinase and tissue inhibitor of metalloproteinase mRNA in human osteoarthritic synovia. J Rheumatol 20, 693-7 (1993)

36. J.F. Woessner,. Jr: Matrix metalloproteinases and their inhibitors in connective tissue remodeling. FASEB $J 5$, 2145-54 (1991)

37. JF Woessner, Jr: Imbalance of proteinases and their inhibitors. In: Osteoarthritic disorders. Eds: Kuettner, KE, Goldberg, VM, American Association of Orthopaedic Surgeons, Rosemont, IL (1995)

38. J. Martel-Pelletier M.-P. Faure, R. McCollum, F. Mineau, J.-M. Cloutier \& J.-P. Pelletier: Plasmin, plasminogen activators and inhibitor in human osteoarthritic cartilage. J Rheumatol 18, 1863-71 (1991)

39. C. A. Towle, M. Wright, A.C. Hecht, S.J. Kuong, L.E.. Pananicolas, R.. Totkovic, H.J. Mankin \& B. V. Treadwell. A matrix metalloproteinase proenzyme activator produced by articular cartilage. Biochem Biophys Res Commun 247, 324-31 (1998)

40. V.C. Knäuper, H. Will, C. Lopez-Otin, B. Smith, S.J. Atkinson, H. Stanton, R.M. Hembry. \& G. Murphy: Cellular mechanisms for human procollagenase-3 (MMP13) activation. Evidence that MT1-MMP (MMP-14) and gelatinase A (MMP-2) are able to generate active enzyme. J Biol Chem 271, 17124-31 (1996)

41. K. Imai, S. Ohta, T. Matsumoto, N. Fujimoto, H. Sato, M. Seiki \& Y. Okada: Expression of membrane-type 1 matrix metalloproteinase and activation of progelatinase A in human osteoarthritic cartilage. Am J Pathol 151, 245-56 (1997)

42. F.H. Büttner, C.E. Hughes, D. Margerie, A. Lichte, H. Tschesche, B. Caterson, \& E. Bartnik:

Membrane type 1 metrix metalloproteinase (MT1-MMP) cleaves the recombinant aggrecan substrate $\operatorname{rAgg} 1_{\text {mut }}$ at the 'aggrecanase' and MMP sites. Biochem $J$ 333, 159-65 (1998)

43. AR Poole, M Alini \& AH Hollander: Cellular biology of cartilage degradation. In: Mechanisms and models in rheumatoid arthritis. Eds: Henderson B, Edwards JCW, Pettipher ER, Academic Press, London (1995)

44. J.B.J. van Meurs, P.L.E.M. van Lent, A.E.M. Holthuysen, I.M. Singer, E.K. Bayne \& W.B. van den 
Berg: Kinetics of aggrecanase- and metalloproteinaseinduced neoepitopes in various stages of arthritis. Arthritis Rheum 42, 1128-39 (1999)

45. A.J.P. Docherty \& G. Murphy: The tissue metalloproteinase family and the inhibitor TIMP: a study using cDNAs and recombinant proteins. Ann Rheum Dis 49, 469-79 (1990)

46. K. J. Leco, R. Khokha, N. Pavloff, S.P. Hawkes \& D.E. Edwards: Tissue inhibitor of metalloproteinase-3 (TIMP-3) is an extracellular matrix-associated protein with a distinct pattern of expression in mouse cells and tissues. $J$ Biol Chem 269, 9352-60 (1994)

47. E. Morunova, A. Tuuttila, U. Bergmann, M. Isopov, Y. Lindqvist, G. Schneider \& K. Tryggvason: Structure of human pro-matrix metalloproteinase-2: activation mechanism revealed. Science 284, 1167-70 (1999)

48. M. Zafarullah, S. Su, J. Martel-Pelletier, J.A. DiBattista, B.G. Costello,W.G. Stetler-Stevenson \& J.-P. Pelletier: Tissue inhibitor of metalloproteinase-2 (TIMP-2) mRNA is constitutively expressed in bovine, human normal, and osteoarthritic articular chondrocytes. $J$ Cell Biochem 60, 211-7 (1996)

49. J. Martel-Pelletier, J.-P. Pelletier \& C.J. Malemud: Activation of neutral metalloprotease in human osteoarthritic knee cartilage. Evidence for degradation in the core protein of sulphated proteoglycan. Ann Rheum Dis 47, 801-8 (1988)

50. F.-X. Gomis-Rüth, K. Maskos, M. Betz, A. Bergner, R. Huber, K. Suzuki, N. Yoshida, H. Nagase, K. Brew, G.P. Bourenkov, H. Bartunik \& W. Bode: Mechanism of inhibition of the human matrix metalloproteinase stromelysin-1 by TIMP-1. Nature 389, 77-81 (1997)

51. G. Rizkalla, A. Reiner, E. Bogoch \& A.R. Poole: Studies of the articular cartilage proteoglycan aggrecan in health and osteoarthritis. Evidence for molecular heterogeneity and extensive molecular changes in disease. $J$ Clin Invest 90, 2268-77 (1992)

52. A.J. Fosang, P.J. Neame, T.E. Hardingham, G. Murphy \& J.A. Hamilton: Cleavage of cartilage proteoglycans between the G1 and G2 domains by stromelysin. J Biol Chem 266, 15579-82 (1991)

53. A.J. Fosang, K. Last, P.J. Neame, G. Murphy, V. Knäuper, H. Tschesche, C.E. Hughes, B. Caterson \& T.E. Hardingham: Neutrophil collagenase (MMP-8) cleaves at the aggrecanase site $\mathrm{E}^{373}-\mathrm{A}^{374}$ in the interglobular domain of cartilage aggrecan. Biochem J 304, 347-51 (1994)

54. A.A. Cole. \& K.E. Kuettner: MMP-8 (neutrophil collagenase) mRNA and aggrecanase cleavage products are present in normal and osteoarthritic human articular cartilage. Acta Orthop Scand 66

(Suppl 266), 98-102 (1995)

55. A.J. Fosang, K. Last, V. Knäuper, G. Murphy \& P.J. Neame: Degradation of cartilage aggrecan by collagenase13 (MMP-13). FEBS Lett 380, 17-20 (1996)

56. M.D. Tortorella, T.C. Burn, M.A. Pratta, I. Abbaszade, J.M. Hollis, R. Liu, S.A. Rosenfeld, R.A. Copeland, C.P. Decicco, R. Wynn, A. Rockwell, F. Yang, J.L. Duke, K. Solomon, H. George, R. Bruckner, H. Nagase, Y. Itoh, D.M. Ellis, H. Ross, B.H. Wiswall, K. Murphy, M.C. Hillman, Jr, G.F. Hollis, R.C. Newton, R.L. Magolda, J.M. Trzaskos \& E.C. Arner: Purification and cloning of aggrecanase-1: A member of the ADAMTS family of proteins. Science 284, 1664-6 (1999)

57. A.P. Hollander, I. Pidoux, A. Reiner, C. Rorabeck, R. Bourne \& A.R. Poole: Damage to type II collagen in ageing and osteoarthritis starts at the articular surface, originates around chondrocytes and extends into the cartilage with progressive degeneration. J Clin Invest 96, 2859-69 (1995) 58. B.V. Shlopov, W.-R. Lie, C.L. Mainardi, A.A. Cole, S. Chubinskaya \& K.A. Hasty: Osteoarthritic lesions. Involvement of three different collagenases. Arthritis Rheum 40, 2065-74 (1997)

59. T.F. Kresina \& C. J. Malemud: Susceptibility of interstitial collagens to rabbit articular chondrocyte collagenase. Collagen Relat Res 4, 453-65 (1984)

60. J.-J. Wu, M.W. Lark, L.F. Chun. \& D. R. Eyre: Sites of stromelysin cleavage in collagen types II, IX, X and XI of cartilage. J Biol Chem 266, 5625-8 (1991)

61. Q. Nguyen, G. Murphy, P.J. Roughley \& J.S. Mort:. Degradation of proteoglycan aggregate by cartilage metalloproteinase; Evidence for the involvement of stromelysin in the generation of link protein heterogeneity in situ. Biochem J 259, 61-7 (1989)

62. P. Witsch-Prehm, R. Miehlke \& H. Kresse: Presence of small proteoglycan fragments in normal and arthritic human cartilage. Arthritis Rheum 35, 1042-52 (1992)

63. G.A. Homandberg, F. Hui \& C. Wen: Cartilage damaging activities of fibronectin fragments derived from cartilage and synovial fluid. Osteoarthritis Cartilage 6, 231-44 (1998)

64.. V.S. Ganu, S.-I. Hu, R. Melton, C. Winter, V.M. Goldberg, T.M. Haqqi \& C.J. Malemud: Biochemical and molecular characterization of stromelysin synthesized by human osteoarthritic chondrocytes in cultured stimulated with rhIL-1 alpha and rhIL-1 beta. Clin Exp Rheumatol 12, 489-96 (1994)

65. H. Ah-Kim, X. Zhang, S. Islam, J.I. Sofi, Y. Glickberg, C.J. Malemud, R.W. Moskowitz \& T.M. Haqqi: Tumor necrosis factor-alpha enhances the expression of hydroxyl lyase, cytoplasmic antiproteinase- 2 and a dual specificity kinase TTK in human chondrocyte-like cells. Cytokine (in press)

66. S.E. Rose, R.O. Williams, L.J. Mason, C. Mauri, L. Marinova-Mutafchieva, A Malfait, R.N. Maini \& M. Feldmann: Suppression of TNF-alpha expression, suppression of Th1 activity, and amelioration of collageninduced arthritis by rolipram. J Immunol 159, 6253-9 (1997)

67. C.I. Westacott, R.M.. Atkins, P.A. Dieppe \& C.J. Elson: Tumor necrosis factor-alpha receptor expression on chondrocytes isolated from human articular cartilage. $J$ Rheumatol 21, 1710-5 (1994)

68. R. Amin: Regulation of tumor necrosis factor-alpha and tumor necrosis factor converting enzyme in human osteoarthritis. Osteoarthritis Cartilage 7, 392-4 (1999)

69. TI Morales: The role of signaling factors in cartilage homeostasis and osteoarthritis. In: Osteoarthritic disorders. Eds: Kuettner KE, Goldberg VM, American Association of Orthopaedic Surgeons, Rosemont, IL (1995)

70. J.-P. Pelletier: The influence of tissue cross-talking on OA progression: role of nonsteroidal antiinflammatory drugs. Osteoarthritis Cartilage 7, 374-6 (1999) 
71. J.W. Larrick \& S.L. Kunkel: The role of tumor necrosis factor and interleukin 1 in the immunoinflammatory response. Pharmaceut Res 5, 129-39 (1988)

72. C.I. Westacott \& M. Sharif: Cytokines in osteoarthritis: mediators or markers of joint destruction? Arthritis Rheum 25, 254-72 (1996)

73. W. Hunter: Of the structure and diseases of articulating cartilages. Phil Trans 42, 514-21 (1743)

74. J.A. Buckwalter \& H.J. Mankin: Articular cartilage: Part II. Degeneration and osteoarthritis, repair, regeneration and transplantation. J Bone Joint Surg [Am] 79, 612-32 (1997)

75. V.M. Goldberg \& A.I. Caplan: Biologic restoration of articular surfaces. AAOS Instruction Course Lectures 48, 623-7 (1999)

76. VM Goldberg \& AI Caplan: Cellular repair of articular cartilage. In: Osteoarthritic disorders. Eds: Kuettner KE, Goldberg VM, American Association of Orthopaedic Surgeons, Rosemont, IL

(1995)

77. D.A.Grande, M.I. Pitman, L. Peterson, D. Menche \& M. Klein: The repair of experimentally produced defects in rabbit articular cartilage by autologous chondrocyte transplantation. J Orthop Res 7, 208-18 (1989)

78. L Rosenberg \& EB Hunziker: Cartilage repair in osteoarthritis: the role of dermatan sulfate proteoglycans. In: Osteoarthritic disorders. Eds: Kuettner K, Goldberg VM, American Association of Orthopaedic Surgeons, Rosemont, IL (1995)

79. A.I. Caplan, M. Elyaderani, Y. Mochizuki, S. Wakitani \& V.M. Goldberg: Principles of cartilage repair and regeneration. Clin Orthop Relat Res 342, 254-69 (1997)

80. A.I. Caplan: Mesenchymal stem cells. J Orthop Res 9, 641-50 (1991)

81. S.L. Lohmander: Cell-based cartilage repair: do we need it, can we do it, is it good, can we prove it? Curr Opin Orthopaedics 9, 38-42 (1998)

82. S. Wakitani, T. Kimura, T. Hirooka, T. Ochi, M. Yoneda, N. Yasui, H. Owaki \& K. Ono: Repair of rabbit articular surfaces with allograft chondrocytes embedded in collagen gel. J Bone Joint Surg [Br] 71, 74-80 (1989)

83. S. Wakitani, T. Goto, S.J. Pineda, R.G. Young, J.M. Mansour, A.I. Caplan \& V.M. Goldberg: Mesenchymal cell-based repair of large, full-thickness defects of articular cartilage. J Bone Joint Surg [Am] 76, 579-92 (1994)

84. M. Brittberg, A. Lindahl, A. Nilsson, C. Ohlsson, O Isaksson \& L. Peterson: Treatment of deep cartilage defects in the knee with autologous chondrocyte transplantation. $N$ Eng J Med 331, 889-95 (1994)

85. M. Brittberg, A. Nilsson, A. Lindahl, C. Ohlsson \& L. Peterson: Rabbit articular cartilage defects treated with autologous cultured chondrocytes. Clin Orthop Relat Res 326, 270-83 (1996)

86. T. Minas \& S. Nehrer: Current concepts in the treatment of articular cartilage defects. Orthopaedics 20, 525-38 (1997)

87. L.A. Solchaga, J. E. Dennis, V.M. Goldberg \& A.I. Caplan: HA-based polymers as cell carriers for tissue engineered repair of bone and cartilage. J Orthop Res (in press) 88. L.A. Solchaga, V.M. Goldberg \& A.I. Caplan: Hyaluronic acid-based biomaterials in tissue engineered cartilage repair. Ital J Sports Med (in press)
89. C.H. Evans, S.C. Ghivizzani, R. Kang, T. Muzzonigro, M.C. Wasko, J. H. Herndon \& P.D. Robbins: Gene therapy for rheumatic diseases. Arthritis Rheum 42, 1-16 (1999)

90. K. Otani, I. Nita, W. Macaulay, H.I. Georgescu, P.D. Robbins \& C.H. Evans: Suppression of antigen-induced arthritis by gene therapy. J Immunol 156, 3558-62 (1996)

91. S.S. Makarov, J.C. Olsen, W.N. Johnson, S.K. Anderle, R.R. Brown, A.S. Baldwin, J.S. Haskill \& J.H. Schwab: Suppression of experimental arthritis by gene transfer of interleukin-1 receptor antagonist cDNA. Proc Natl Acad Sci U S A 93, 402-6 (1996)

92. F.Apparailly, C. Verwaerde, C. Jacquet, C. Auriault, J. Sany \& C. Jorgensen: Adenovirus mediated transfer of viral IL-10 gene inhibits murine collagen-induced arthritis. J Immunol 160, 5213-20 (1998)

93. C.H. Evans, P.D. Robbins, S.C. Ghivizzani, J.H. Herndon, R. Kang, A.B. Bahnson, J.A. Barranger, E.M. Elders, S. Gay, M.M. Tomaino, M.C. Wasko, S.C. Watkins, T.L. Whiteside, J.C. Glorioso, M.T. Lotze \& T.M. Wright: Clinical trial to assess the safety, feasibility and efficacy of transferring a potentially anti-arthritic cytokine gene to human joints with rheumatoid arthritis. Hum Gen Ther 7, 1261-80 (1996)

94. M. McCarthy: Gene therapy for rheumatoid arthritis starts clinical trials. Lancet 348, 323 (1996)

95. U. Müller-Ladner, C.H. Evans, B.N. Franklin, B.N. Franklin, C.R. Roberts, R.E. Gay, P.D. Robbins \& S. Gay: Gene transfer of cytokine inhibitors into human synovial fibroblasts in the SCID mouse model. Arthritis Rheum 42, 490-7 (1999)

96. Y. Chernajovsky, G. Adams, O. Podhajcer, G. Mueller, P.D. Robbins \& M. Feldman: Inhibition of transfer of collagen-induced arthritis into SCID mice by gene transfer of spleen cells with retrovirus expressing soluble human tumor necrosis factor receptor. Gene Ther 2, 731-5 (1995) 97. L.W. Moreland, S.W. Baumgartner, M. H. Shiff, E. A. Tindall, R.M. Fleischmann, A.L. Weaver, R.E. Ettlinger, S. Cohen, W.J. Koopman, K. Mohler, M.B. Widmer \& C.M. Blosch: Treatment of rheumatoid arthritis with recombinant human tumor necrosis factor receptor (p75)-Fc fusion protein. N Eng J Med 337, 141-7 (1997)

98. X.Y. Song, M. Gu, W.W. Jin, M. Klinman \& S.M. Wahl: Plasmid DNA encoding transforming growth factorbeta $_{1}$ suppresses chronic disease in a streptococcal cell wall-induced arthritis model.

J Clin Invest 101, 1-7 (1998)

99. Y. Chernajovsky, G. Adams, K. Triantaphyllopoulos, F. Ledder \& O.L. Podhajcer: Pathogenic lymphoid cells engineered to express TGF-beta ${ }_{1}$ ameliorate disease in a collagen-induced arthritis model. Gene Ther 4, 553-9 (1997)

100. C.J. Malemud, W. Killeen, T.M. Hering \& A.F. Purchio: Enhanced sulfated-proteoglycan core protein synthesis by incubation of rabbit chondrocytes with recombinant transforming growth factor-beta ${ }_{1}$ J Cell Physiol 149, 151-9 (1991)

101. C.J. Malemud, S. Stevenson, F. Mehraban, R.S. Papay, A.F. Purchio \& V.M. Goldberg: The proteoglycan synthesis repertoire of rabbit chondrocytes maintained in Type II collagen gels. Osteoarthritis Cartilage 2, 29-42 (1994) 
102. R. Kang, S.C. Ghivizzani, J.H. Herndon, P.D. Robbins \& C.H. Evans: Gene therapy for arthritis: principles and clinical practice. Biochem Soc Trans 25, 533-7 (1997)

103. J.-P. Pelletier, J.P. Caron, C.H. Evans, P.D. Robbins, H.I. Georgescu, D. Jovanovic, J.C. Fernandes \& J. MartelPelletier: In vivo suppression of early experimental osteoarthritis by interleukin-1 receptor antagonist using gene therapy. Arthritis Rheum 40, 1012-9 (1997)

104. R. Kang, T. Marui, S.C. Ghivizanni, I.M. Nita, H.I. Georgescu, J.K. Suh, P.D. Robbins \& C.H. Evans: Ex vivo gene transfer to chondrocytes in full-thickness articular cartilage defects: a feasibility study. Osteoarthritis Cartilage 5, 139-43 (1997)

105. T. Tomita, H. Hashimoto, N. Tomita, R. Morishita, S.B. Lee, K. Hayashida, N. Nakamura, K. Yonenobu, Y. Kaneda \& T. Ochi: In vivo direct gene transfer into articular cartilage by intraarticular injection mediated by HVJ (Sendai virus) and liposomes. Arthritis Rheum 40, 901-6 (1997)

106. S.S. Boggs, K.D. Patrene, G.M. Mueller, C.H. Evans, L.A. Doughty \& P.D. Robbins: Prolonged systemic expression of human Il-1 receptor antagonist protein in sera of lethally irradiated mice reconstituted with hematopoietic stem cells transduced with a retrovirus containing the Il-1ra gene. Gen Ther 4, 252-7 (1997)

Key Words: Cartilage, Repair, Osteoarthritis, Gene Therapy, Review

Send correspondence to: Dr Charles J. Malemud, Ph.D. Biomedical Research Bldg. Rm. 1025E, Case Western Reserve University School of Medicine, Cleveland, $\mathrm{OH}$ 44106-4946, Tel:216-368-1372 Fax: 216-368-1333, Email: cjm4@po.cwru.edu

Received 8/23/99 Accepted 8/31/99 